\section{Concepções sobre o tráfico de mulheres para fins de exploração sexual: um estudo com representantes institucionais no Brasil e em Portugal}

\author{
Concepts in women trafficking for sexual \\ exploitation: a survey with institutional \\ representatives in Brazil and Portugal
}

Concepciones sobre el tráfico de mujeres para fines de explotación sexual: un estudio con representantes institucionales en Brasil $y$ en Portugal

\begin{abstract}
Resumo
Este artigo investiga as concepções sobre o tráfico de mulheres para fins de exploração sexual, na ótica de representantes de instituições governamentais e não governamentais que atuam na construção de políticas de enfrentamento, na prevenção e no acolhimento das vítimas, no Brasil e em Portugal. Foi efetuado um estudo exploratório de natureza qualitativa, com o objetivo de identificar os discursos institucionais referentes às concepções sobre o tráfico de mulheres para fins de exploração sexual usando-se uma análise temática. Observou-se imprecisão conceitual nas concepções dos entrevistados sobre tráfico de mulheres para fins de exploração sexual, ignorando por vezes os direitos das trabalhadoras do sexo em migrar para trabalhar em outros países. Não há consenso entre as instituições sobre o perfil de vítima de tráfico, marcado por estereótipos; sua delimitação é influenciada pela legislação e pelo controle de fronteiras. Maior precisão conceitual minimizaria o papel de valores morais, nortearia políticas públicas mais adequadas e eficientes, bem como facilitaria a atuação dos técnicos no atendimento às vítimas.
\end{abstract}

Tráfico de Pessoas; Violência Sexual; Vítimas de Crime; Mulheres
Jose Gonçalo Pais Estrela da Silveira Zúquete 1 Edinilsa Ramos de Souza 2 Suely Ferreira Deslandes 1 


\section{Introdução}

Este artigo objetiva investigar as representações sociais sobre o tráfico de mulheres para fins de exploração sexual na ótica de representantes de instituições governamentais e não governamentais, que atuam na construção de políticas de enfrentamento, na prevenção e no acolhimento das vítimas, no Brasil e em Portugal.

No ano 2000, o tráfico de seres humanos foi definido no protocolo adicional à Convenção das Nações Unidas contra o Crime Organizado Transnacional relativo à prevenção, repressão e punição do tráfico de pessoas, em especial de mulheres e crianças, conhecido como Protocolo de Palermo. Segundo esse documento, o tráfico de seres humanos se refere ao "recrutamento, transporte, transferência, alojamento ou acolhimento de pessoas, recorrendo à ameaça ou uso de força ou a outras formas de coação, ao rapto, à fraude, ao engano, ao abuso de autoridade ou à situação de vulnerabilidade ou à entrega ou aceitação de pagamentos ou benefícios para obter o consentimento de uma pessoa que tenha autoridade sobre outra, para fins de exploração" 1 (p. 13).

Devido à abrangência da definição, suas implicações socioeconômicas, bem como pela dificuldade de operacionalizar com precisão esse conceito, percebe-se que não há consenso nem posições isentas de vinculações ideológicas e morais quanto ao que se entende por tráfico de seres humanos. Para alguns autores, ele está permeado pelas diferentes pautas de reivindicações dos movimentos sociais, que o entendem como tráfico de mulheres e o debatem no âmbito da prostituição, ora sendo a favor da discriminalização desta prática, considerando-a como um trabalho merecedor de direitos, ora sendo contra e tratando-a como expressão da violência de gênero $2,3,4$.

Pelas dificuldades mencionadas, as estimativas mundiais relativas ao tráfico de seres humanos também não são consensuais e os números oscilam bastante. Elas frequentemente são usadas com finalidade política eleitoral e incluem pessoas imigrantes não documentadas e trabalhadores da indústria do sexo como sendo vítimas de tráfico 2 . Essa conotação está mais presente nos países europeus do que no Brasil, devido às divergências quanto à gestão da questão migratória nos dois continentes, o que, certamente, interfere diretamente nas ações de enfrentamento. Um relatório 5 baseado em 26 organizações internacionais, aponta que cerca de 1 milhão de pessoas que migram anualmente para a Europa acabam sendo forçadas à prostituição. Esse elevado montante costuma ser associado ao tráfico e parece ter, entre outros objetivos, o de chamar a atenção para o problema da migração e da prostituição nessa região, e para a necessidade de controlar tais fenômenos.

Os números são bem menores quando se considera o Brasil, país mais identificado como de origem das pessoas traficadas/prostituídas, e Portugal, país primordialmente de destino destas mulheres. No Brasil, entre 2005 e 2011, a Divisão de Assistência Consular do Ministério das Relações Exteriores identificou 337 brasileiras/os vítimas de tráfico para fins sexuais ${ }^{6}$. No ano de 2012, o Ministério da Saúde contabilizou o atendimento de 130 vítimas e o Ministério do Desenvolvimento Social e Combate à Fome registrou 292 pessoas vítimas de tráfico 7. Em Portugal, no ano de 2013, foram sinalizadas 308 presumíveis vítimas de tráfico de seres humanos, das quais 55 se referiam a mulheres traficadas para fins de exploração sexual 8 .

Portanto, este estudo busca contribuir para o debate sobre as concepções dos agentes de instituições governamentais e não governamentais acerca do que entendem como tráfico de mulheres para fins de exploração sexual, sobre os motivos destas mulheres para o envolvimento com o tráfico e sobre o suposto perfil das mesmas. No presente artigo, entende-se que as representações de agentes governamentais e não governamentais subsidiam uma visada crítica sobre as práticas de operacionalização das políticas oficiais.

\section{Material e método}

Realizou-se um estudo exploratório de natureza qualitativa, no Brasil e em Portugal, com o objetivo de identificar os discursos institucionais referentes às representações sociais sobre o tráfico de mulheres para fins de exploração sexual.

Entende-se por representações sociais a reprodução de uma perceção retida na lembrança ou do conteúdo do pensamento 9 .

A amostra pesquisada buscou contemplar representantes de organizações governamentais (OG) e não governamentais (ONG) de ambos os países, com reconhecida atuação em relação ao tema estudado, tanto nas políticas públicas como no atendimento direto às vítimas de tráfico (Tabela 1). Para selecionar as instituições, foi feita uma consulta prévia a atores-chave de ambos os países, a fim de contemplar a diversidade quanto à natureza das mesmas (OG e ONG), como em relação à sua atuação direta junta às vítimas e/ou na construção de políticas públicas.

Buscou-se também identificar semelhanças e distinções entre os relatos de atores que respondem oficialmente e aqueles que atuam na 
Tabela 1

Organizações pesquisadas.

\begin{tabular}{|c|c|c|}
\hline País & OG & ONG \\
\hline \multirow[t]{10}{*}{ Brasil } & - Núcleo de Enfrentamento Estadual ao Tráfico de & - Projeto Trama (Rio de Janeiro) \\
\hline & Pessoas (Rio de Janeiro) & - Associação Brasileira de Defesa da Mulher, da Infância e da Juventude \\
\hline & - Posto Avançado de Atendimento ao Migrante do & (São Paulo) \\
\hline & Aeroporto Galeão (Rio de Janeiro) & \\
\hline & - Posto Avançado de Atendimento ao Migrante do & \\
\hline & Aeroporto de Guarulhos (São Paulo) & \\
\hline & - Núcleo de Enfrentamento Estadual ao Tráfico de & \\
\hline & Pessoas (São Paulo) & \\
\hline & - Núcleo de Enfrentamento Estadual ao Tráfico de & \\
\hline & Pessoas (Bahia) & \\
\hline \multirow[t]{3}{*}{ Portugal } & - Polícia Judiciária & - Associação de Apoio à Vítima \\
\hline & - Serviço de Estrangeiros e Fronteiras & - Associação de Planeamento Familiar \\
\hline & - Comissão de Igualdade de Gênero & \\
\hline
\end{tabular}

OG: organização governamental; ONG: organização não governamental.

militância dos movimentos sociais em relação ao tráfico de mulheres para fins de exploração sexual. A amostra de Portugal é menor (sete instituições) que a do Brasil (12), tendo em vista as diferentes dimensões destes países e o número de organizações neles existentes. Também o montante de ONG (quatro) é menor que o de OG (15); estas instituições entrevistadas foram selecionadas de acordo a sua importância de atuação no tráfico de mulheres para fins de exploração sexual.

Utilizou-se a técnica de entrevista semiestruturada, na qual o pesquisador baseia-se em um roteiro temático, com liberdade para introduzir questões com a finalidade de precisar conceitos ou obter mais informações sobre os temas desejados 10. Para Minayo 11, o roteiro é sempre um guia, que deve ser flexível quanto à ordem das suas questões. Na pesquisa maior, da qual este estudo faz parte, foi utilizado um roteiro de entrevista contendo 11 questões norteadoras. Entretanto, para os objetivos deste artigo foram selecionadas apenas três delas: (1) "Com que concepções de tráfico de mulheres para fins de exploração sexual esta instituição trabalha?"; (2) "Em sua opinião, o que leva estas mulheres a serem traficadas para fins sexuais? Como elas chegam a esta situação?"; e (3) "A partir da sua experiência de atuação, quais são as características das mulheres traficadas para fins sexuais (idade, situação conjugal, filhos, raça/cor, classe social)?".

Inicialmente, foram feitos contatos com as instituições a fim de conseguir autorização pa- ra a realização das entrevistas. Uma vez obtidas, procedeu-se o agendamento e a realização das entrevistas nas próprias instituições ou em lugares escolhidos pelo entrevistado, que foram gravadas e duraram, em média, 40 minutos. A maior dificuldade do campo foi conciliar a agenda do pesquisador com a dos representantes de cada instituição, pelo fato do estudo ser realizado em distintas cidades dos dois países.

As entrevistas foram aplicadas a 12 representantes de instituições brasileiras localizadas nos estados da Bahia, Rio de Janeiro e São Paulo, e em Brasília (Distrito Federal), dos quais dez são agentes governamentais e dois não governamentais. Em Portugal, foram realizadas sete entrevistas em instituições do Algarve, Lisboa e Porto, sendo cinco com representantes de OGs e duas com agentes não governamentais (Tabela 1). Cada representante entrevistado foi devidamente esclarecido sobre a sua participação no estudo e assinou o Termo de Consentimento.

As entrevistas foram transcritas e processadas. Visando a proteger a identidade dos depoentes, optou-se por identificar apenas a origem da instituição (se OG ou ONG) e o país de origem (Brasil ou Portugal).

Foi efetuada uma análise temática 12 , que tem como finalidade trazer os significados e sentidos atribuídos nos relatos sobre o tema em questão. Numa primeira etapa foi realizada uma pré-análise dos textos por meio de uma leitura flutuante, e constituído um córpus do universo estudado para dar respostas aos objetivos deste estudo. Numa segunda fase, o material foi explorado for- 
mulando-se e reformulando hipóteses, e categorizando-se os temas da análise. Por fim, foi feito o tratamento dos resultados usando-se inferência e interpretação 13 .

Os temas analisados foram: (1) Concepções dos representantes das instituições sobre o que é tráfico de mulheres para fins de exploração sexual, no qual emergiu a categoria conceito legal; (2) Motivos que levam essas mulheres a serem traficadas, que abrangeu as categorias condições econômicas, a busca de sonhos e as redes de tráfico; e (3) Nas concepções sobre o perfil das mulheres vítimas de tráfico aparecem dois grupos de depoimentos: um que não caracteriza este perfil e outro que o define com base em suas experiências práticas.

A pesquisa a qual o presente artigo se vincula foi aprovada pelo Comitê de Ética em Pesquisa do Instituto Nacional de Saúde da Mulher, da Criança e do Adolescente Fernandes Figueira, Fundação Oswaldo Cruz, sob o parecer no 684.978 .

\section{Resultados}

\section{Concepções do tráfico}

Embora ambos os países sigam o Protocolo de Palermo como linha orientadora das políticas de tráfico, no Brasil o código penal vigente, datado de 1940, revisto pela Lei no 12.015 14, de 2009 , trata da punição a quem promove, intermedia ou facilita a entrada, no território nacional, de pessoa que venha a exercer a prostituição ou a saída de pessoa para exercê-la no estrangeiro. Ou seja, o foco dado ao tráfico se circunscreve ao tratamento da prostituição, e esta dissonância é questionada pelas instituições que atuam na área. Portugal adotou o Protocolo de Palermo na sua lei de tráfico, e isto muda a problematização do fenômeno trazida pelos representantes:

"A política nacional segue o Protocolo de $\mathrm{Pa}$ lermo, né?; e aí definição do que o protocolo dá sobre tráfico de pessoas. (...) aí tem a dissonância com o nosso Código Penal" (OG/Brasil).

"É o conceito legal (...) o nosso está totalmente em linha com o Protocolo de Palermo, até vai mais à frente no ponto de vista depois das penalizações... Portanto está completamente em consonância" (OG/Portugal).

Os entrevistados das instituições brasileiras reconheceram a necessidade de adequação legislativa ao Protocolo de Palermo, a fim de suprimir a criminalização dos trâmites migratórios para fins de prostituição, desvinculando-os das formas de exploração sexual. Entretanto, há dificuldades na operacionalização prática dessa distinção, sendo frequentemente mencionado que a linha entre prostituição e tráfico para fins de exploração sexual é muito tênue.

"Porque no nosso país, realmente o fenômeno que tá lá como tráfico, ele é muito inadequado. Que é o simples fato de você auxiliar alguém a se deslocar pra exercer prostituição, ou seja, a finalidade em si que é essencial, a exploração, o fator do engano, então isso não está no nosso código penal" (OG/Brasil).

Observou-se nas falas dos entrevistados a pouca referência aos planos nacionais de enfrentamento do tráfico de mulheres para fins de exploração sexual e como eles definem o conceito de tráfico. No Brasil, o primeiro Plano Nacional de Enfrentamento ao Tráfico de Pessoas (PNETP) foi implantado em 2006, e implementado de 2006 a 20101 . Atualmente, está vigente o segundo plano, alinhado com o Protocolo de Palermo. Portugal adotou em 2007 o primeiro Plano Nacional Contra o Tráfico de Seres Humanos (2007-2010). Atualmente, está em vigor o terceiro Plano Nacional de Prevenção e Combate ao Tráfico de Seres Humanos, 2014-2017.

Outro fator que agrega complexidade ao debate são as leis proibitivas dos países de destino desses fluxos de mulheres que praticam a prostituição, o que pode influenciar na negação dessa atividade profissional como prática autônoma, criando uma perspectiva irrealista de vitimização. A imposição, por parte do agenciador no mercado do sexo, de regras e condições de trabalho desfavoráveis às profissionais que estabelecem uma relação contratual de trabalho, pode também ser confundida com a exploração sexual ou o tráfico de mulheres para fins de exploração sexual.

“E o que eu vejo muito, que acontece na Europa, é uma confusão entre prostituição forçada, prostituição autônoma e tráfico pra fins de exploração sexual. Existe uma grande confusão (...) praticamente toda prostituta era considerada vítima de tráfico..." (ONG/Brasil).

Algumas instituições problematizaram que não somente o Protocolo de Palermo define os critérios para a nomeação do fenômeno e para a identificação das mulheres na condição de tráfico. Interferem nessa classificação os serviços que operam as políticas públicas do país onde foram acolhidas as vítimas no exterior. Assim, a mulher seria repatriada já com uma classificação prévia e "oficial” de sua condição, atribuída pelos serviços daquele país.

Foi também referido como entrave para a definição do conceito de tráfico a pouca distinção entre as diversas relações de exploração da força de trabalho no mercado da prostituição e a exploração, que realmente definiriam os contornos do tráfico de pessoas. O Protocolo de 
Palermo pouco define o que é exploração e cada um pode decidir o que entende ser ou não um caso de tráfico. Alguns entrevistados optam por delimitar contornos extremos, como o da exploração associada à escravidão ou perda de liberdade.

“Como o artigo né, do Protocolo de Palermo, ele deixa em aberto (...). Eu acho que a questão do trabalho escravo seja ele em que ramo for. Eu acho que serve como parâmetro pra gente definir essa exploração que existe no Protocolo de Palermo" (ONG/Brasil).

Sobre os motivos que levam mulheres a se tornarem vulneráveis ao tráfico para a exploração sexual

Os entrevistados enfatizaram três motivos que podem agir sinergicamente e levariam as mulheres a se tornarem vítimas do tráfico de mulheres para fins de exploração sexual. Excepcionalmente, alguns entrevistados consideraram ser arriscado estabelecer os motivos que levam ao tráfico de mulheres para fins de exploração sexual, apontando como necessárias as pesquisas etnográficas para qualificar a compreensão do fenômeno.

\section{- As condições econômicas}

O motivo mais frequentemente citado, tanto no Brasil como em Portugal, aponta as vulnerabilidades relacionadas às situações financeiras precárias, necessidades sociais e econômicas não atendidas. As OG e as ONG apontam tais condições como o principal motivo da migração dessas mulheres, associadas à idealização de uma vida melhor.

"Ela tem poucas condições econômicas. Ela tem que sustentar a família, ou o filho, ou a mãe (...). Acaba sendo muito tentador a oportunidade, a possibilidade de ganhar muito mais, em muito pouco tempo" (OG/Brasil).

"A esperança de que mesmo uma situação abusiva fosse melhor do que a situação que as pessoas vivem no país onde estão" (ONG/Portugal).

Verificou-se que esses circuitos transfronteiriços têm na sua essência um lugar de origem associado a vulnerabilidades sociais e um lugar de destino que traz a possibilidade de maiores rendimentos.

No entanto, foi também referido que existem casos de pessoas com uma boa condição social que pretenderiam manter ou aumentar seus rendimentos por meio da prostituição.

"Um complemento de rendimento, e quando digo isto, estou a falar de alguma situação de nível social alto, estou a falar, se calhar, de algumas estudantes universitárias, estou a falar de gente que trabalha normalmente, e à noite tem aquela atividade" (OG/Portugal).

\section{- Em busca dos sonhos}

O sentido de uma concepção fantasiosa ou muito idealizada foi enfatizada pela palavra "sonho", tanto por representantes de ONG como de OG, de ambos os países, reforçando a ideia de ilusão construída por promessas enganosas que favoreceriam a adesão às propostas de aliciamento.

"É um sonho você morar no exterior. Você conseguir ajudar a família. Eu acho que é muito nesse contexto" (OG/Brasil).

"Ainda vem com uma questão de um sonho delas de melhorar de vida; a proposta ser encantadora..." (OG/Brasil).

Também foram mencionados aspectos referentes a uma concepção cultural colonizada, sustentando a crença de que nos países do exterior haveria condições superiores de vida.

“A característica do colonizado. A imagem de que tudo que vem de fora, o que é estrangeiro é melhor. Viver fora do Brasil é melhor. Um homem estrangeiro é um homem que vai me dar uma oportunidade que o brasileiro não dá. São essas (...) situações, muitas vezes equivocadas" (OG/Brasil).

\section{- As redes de tráfico}

O terceiro motivo invocado para o favorecimento ao tráfico de mulheres para fins de exploração sexual foi o conjunto de ações e estratégias das redes de tráfico que agiriam tanto de maneira informal como organizada. Os aliciadores das redes aparecem como pessoas conhecedoras do país de origem e de destino das vítimas, e frequentemente têm com elas uma relação de amizade ou confiança. A via informal surge a partir de conversas com conhecidos ou mesmo de forma virtual através de redes sociais:

"Conversou com a comadre, conversou com a manicure, conversou com a fulaninha, com o fulaninho (...). Então a gente tem as redes sociais...” (OG/Brasil).

"Na verdade tem de ser alguém que conhece bem a origem, conhece bem as pessoas, conhece bem as famílias e o meio de onde elas vêm e depois conhece também o destino" (OG/Portugal).

Representantes de instituições do Brasil e de Portugal referiram ser frequente a ação de mulheres que estiveram anteriormente na condição de exploração sexual e passam depois a ser aliciadoras. Esse aliciamento é favorecido pela divulgação de exemplos de sucesso e dos bens materiais e riqueza conseguidos com o trabalho sexual no exterior. 
Alguns entrevistados portugueses estabeleceram um contraponto entre as redes formais, especialmente do Leste Europeu (tidas como mais violentas), e as redes informais, mais atuantes no Brasil.

"Não existe propriamente, especialmente do Brasil, uma rede propriamente estratificada do ponto de vista como a máfia do Leste em que tem as coisas muito mais claras num sistema de pirâmides, muito mais organizadas" (OG/Portugal).

Atenuando os depoimentos anteriores, foi referido por entrevistados de ambos os países que as redes de tráfico de mulheres para fins de exploração sexual não são em sua maioria estruturadas e violentas, mas se referem a situações de comércio de trabalho, ao contrário do exemplo das redes do tráfico de drogas.

"Temos poucas situações, por exemplo, de rapto ou situações assim de uma violência mais (...). Mas, por norma, quer na exploração laboral, quer na exploração sexual, são situações de comércio, de trabalho" (OG/Portugal).

"Existe uma mínima organização, mas não dá pra você ver efetivamente se é uma organização muito refinada, muito rebuscada, como pode ser, por exemplo, um crime internacional de tráfico de drogas" (OG/Brasil).

\section{Da invisibilidade à generalização: como a} mulher traficada é retratada?

A confusão conceitual estabelecida em torno do tráfico de seres humanos, bem como da especificidade do tráfico de mulheres para fins de exploração sexual, reflete-se na dificuldade em definir quem são e que características têm as pessoas submetidas a essa condição.

Nos depoimentos surgiram relatos diversificados que se agregaram em torno de duas posições: uma em que esse perfil não pode ser caracterizado, e outra na qual os depoentes o constroem com base em suas práticas.

No primeiro desses grupos, agrega-se um maior contingente de depoentes cujos relatos defendem que ainda não pode ser definido um perfil, seja pela diversidade, seja devido à pequena amostra a que essas instituições tiveram acesso, e ainda pela criminalização desse fenômeno, que dificulta tanto a sua visibilidade como a daqueles nele envolvidos.

"Não considero que exista um perfil. (...) por nossa experiência nós já tivemos pessoas licenciadas, já tivemos pessoas analfabetas, com muito pouca escolaridade, com muita escolaridade" (ONG/Portugal).

"Eu acho que é muito difícil de construir um perfil, vamos dizer, mais específico dessas mulheres traficadas. Por quê? Bom, o tráfico é um crime muito invisível, pouco conhecido e geralmente associado a outros tipos penais...” (OG/Brasil).

Alguns depoimentos de representantes de OG brasileiras destacaram a complexidade do fenômeno como entrave à construção de uma concepção mais clara sobre quem são essas pessoas que, por vezes, são confundidas aos casos de prostituição. No entanto, a vulnerabilidade social das vítimas de tráfico para fins sexuais é um tema que sobressai nos relatos em ambos os países.

Em Portugal foi destacada, tanto por agentes de OG como de ONG, a variabilidade do grupo vitimizado ao longo do tempo. Mais recentemente, observou-se que a crise econômica tem mostrado uma mudança nesse perfil, em que perde centralidade a mulher traficada para fins de exploração sexual e passa a ser mais frequente a exploração laboral masculina.

Essa constatação é confirmada por representante de uma instituição de Portugal que ressaltou que a lógica do mercado - procura e oferta - determina quem são as pessoas a serem traficadas e que este grupo é variável em função desta lógica.

"Não, eu não acho que existam perfis em termos de mulher vítima de tráfico. Eu acho que isto funciona numa lógica de mercado (...). Acho que o que define aqui o perfil é a procura que pode existir do cliente e isso define o seu perfil" (OG/Portugal).

Outra dificuldade alegada pelos representantes de algumas instituições para a identificação e a caracterização desse grupo de vítimas é a pouca capacitação ou mesmo o despreparo dos técnicos que usam diferentes noções sobre o tráfico de mulheres para fins de exploração sexual dependendo do seu campo de atuação, problema verificado inclusive no setor saúde.

"Muitas vezes a gente tem que ligar pra conversar com o técnico porque, às vezes (...) aqui, por exemplo, a gente tem oitenta casos. Nossa! Oitenta casos em um mês é uma coisa muito estranha! $O$ que eles estão entendendo por tráfico de pessoas?" (OG/Brasil).

"E os profissionais têm sim dificuldades em relação ao preenchimento da notificação, até porque tem muito o problema (...) do medo, do tabu, é (...) de não saber que é compulsório, o desconhecimento da ficha e às vezes até o desconhecimento da violência como problema de saúde pública, da violência como objeto de notificação" (OG/Brasil).

Entre os depoentes que caracterizaram as mulheres traficadas é interessante perceber que suas representações concebem o Brasil como um país de origem das vítimas que migraram para outros países. Para eles, Portugal teria uma condição oposta, a de um país receptor das mulheres capturadas pelas redes de traficantes do Brasil e 
do Leste europeu. Nesse grupo de relatos se destaca a referência às condições socioeconômicas vulneráveis desses países:

"São estrangeiras na sua maioria, e quanto à nacionalidade, temos situações do Brasil, verdade, mas também do (...) Leste europeu, nomeadamente da Romênia. São normalmente mulheres cuja origem é de uma condição social baixa, nãoé? Que vêm, às vezes, com problemas de inserção na sociedade, nos países de origem" (OG/Portugal).

Representantes brasileiros, mais que os de Portugal, caracterizaram as vítimas do tráfico como sendo preferencialmente mulheres, na faixa dos 20 aos 40 anos, afro-descendentes (de cor negra ou parda), com baixa escolaridade, mal remuneradas em seus empregos ou sem emprego, casadas, com ou sem filhos, residentes na periferia das cidades do seu país de origem. Portanto, segundo sua visão, são pobres e vulneráveis socioeconômica e psicologicamente.

"Sem filhos, mulheres na faixa de 30, 40 anos..." (OG/Brasil).

"Geralmente elas deixam seus filhos aqui no Brasil (...). Faixa etária a partir dos 30 anos (...) dos 25 a 30" (OG/Brasil).

"Têm um estereótipo (...) que ela [mulher negra] é sexualmente mais interessante, (...) mais lasciva, então (...) além do elemento social, das vulnerabilidades sociais, também uma questão mais subjetiva, do imaginário que se tem dessa mulher" (OG/Brasil).

Apenas um representante de uma OG brasileira mencionou os transexuais como um grupo que no atendimento da instituição é mais numeroso que o das mulheres.

"Transexuais também eu acho que é até a maioria, foi mais transexuais do que mulheres..." (OG/Brasil).

É importante ressaltar que suas representações estão constituídas por uma imagem de mulher traficada como aquela que pertence a um grupo socioeconômico pobre e que busca nas redes formais ou informais um modo de sair do país, a fim de melhorar as suas condições de vida e as de sua família. No entanto, uma fragilidade da qual esse perfil padece é o fato de se basear no pequeno número de casos de tráfico de mulheres para fins de exploração sexual com os quais as instituições lidam.

“Nós não temos muitos casos porque as denúncias são poucas” (OG/Brasil).

\section{Discussão}

Conforme ficou evidenciado, o tráfico de mulheres para fins de exploração sexual tem sido um tema de complexa definição, difícil operaciona- lização e costuma ser confundido com situações de migração para prostituição ou de imigrantes sem documentação 15,16.

Emma Goldman, desde os primórdios dos debates sobre o tráfico de mulheres nos idos de 1910, já comentava que na gênese deste problema estava a desigualdade de gênero, perpassada pelos valores morais da época. Essa autora considerava que a desigualdade de gênero se refletia tanto no mundo do trabalho como na vida familiar, e também estava associada à criminalização da prostituição e da imigração de mulheres sozinhas 17 .

O tráfico de mulheres para fins de exploração sexual também é um fenômeno cuja definição está ligada à pauta de movimentos sociais, ao escopo legal de cada país, aos consensos definidos em tratados internacionais e aos valores morais e sociais que variam historicamente, consoante os debates, interesses políticos e as mudanças nas condições econômicas globais 3,18.

Contemporaneamente, o conceito adotado no Protocolo de Palermo constitui um parâmetro para os que atuam com o tema, conforme percebeu-se entre os representantes das instituições entrevistados. Entretanto, restam dúvidas sobre a conceituação do tráfico de mulheres para fins de exploração sexual, geradas pela imbricação entre termos e fenômenos distintos, especialmente no que concerne à prostituição e à exploração sexual 19,20 .

Em termos de fluxos globais tem sido crescente a presença da mulher imigrante, que busca no exterior as oportunidades que não encontram em seu país de origem. São circuitos que têm em comum o fato de serem rentáveis e gerarem benefícios para os que os promovem. Neles, incluise o tráfico ilegal de pessoas destinado ao mercado do sexo, assim como vários tipos de trabalho no mercado formal e informal 21 .

A associação do tráfico com a criminalização da prostituição, descrita no código penal brasileiro, foi referendada de forma crítica pelos entrevistados, assim como por autores e representantes de movimentos sociais que lembram que o discurso antitráfico associado ao combate à prostituição muitas vezes fortalece ações antimigratórias e xenofóbicas 22,23,24. Tanto no Brasil como em Portugal a prostituição não é uma atividade ilegal, mas sim as práticas realizadas por aqueles que querem promovê-la para usufruir de seus lucros.

Em Portugal, o tema da mulher traficada começou a ter destaque a partir da migração das mulheres do Leste europeu, seguidas pelas oriundas do Brasil, que vieram trabalhar na prostituição 25,26. Atualmente, a maioria das supostas vítimas de tráfico sexual em Portugal é de nacio- 
nalidade brasileira, seguidas das que vêm do Leste Europeu e da África, sobretudo da Nigéria 27. O tráfico de seres humanos envolve o tráfico para fins de trabalho escravo, tráfico de órgãos e tráfico para fins de exploração sexual. Nota-se que tanto no Brasil como em Portugal tem havido uma mudança na tipificação das vítimas de tráfico de seres humanos, registrando-se um acréscimo de vítimas do gênero masculino para fins de trabalho escravo 7,8

Parte da população que é aliciada pelas redes de tráfico sabe que vai trabalhar na prostituição. Entretanto, elementos subjetivos atuam na decisão dessas mulheres, conforme ficou claro neste estudo. Muitas delas são movidas pelo sonho de uma vida melhor, de conhecer outros países e de neles conseguir se casar 2 .

Agustín 2 reconhece que os lucros obtidos na indústria do sexo são mais elevados que os de muitos outros trabalhos e, para muitas dessas mulheres, optar por este caminho significa a possibilidade de ajudar os pais, ter os filhos na escola, construir ou comprar casa para ela ou sua família morar, abrir pequenos negócios e viver com melhor padrão de vida.

Para Sassen 21, os atores-chave que emergem dessas condições sociais frágeis são as mulheres, as redes de tráfico, empresários e os governos dos países envolvidos. A autora denomina de contrageografias esses circuitos, os quais considera estarem profundamente enraizados em algumas das principais dinâmicas da globalização, como a formação de mercados globais, a intensificação de redes transnacionais e translocais, e o desenvolvimento de tecnologias de comunicação, que permitem inúmeras facilidades para o controle e gestão dos negócios da indústria do sexo.

Sobre a atuação das redes no tráfico para exploração sexual internacional, verifica-se que nos fluxos entre a América Latina e a Europa o Brasil é sobretudo um país "exportador", enquanto Portugal é predominantemente "receptor".

Os relatos dos entrevistados demonstram que a maioria das redes entre Brasil e Portugal funciona de modo informal, ao contrário das do Leste Europeu. Isso é corroborado por estudos que indicam que tais redes são compostas por pessoas de ambas as nacionalidades e por várias ramificações nos países de origem, havendo mulheres envolvidas no aliciamento 25,28. De acordo com o mencionado pelos entrevistados, com frequência os aliciadores são pessoas próximas ao contexto familiar da vítima.

$\mathrm{Na}$ realidade do Leste Europeu, de acordo com Malarek 29, em alguns países como a Rússia, Ucrânia e Moldávia, o tráfico de mulheres para fins de exploração sexual é movido pelo imenso desespero e o desejo destas mulheres de terem uma vida melhor, situação da qual as redes organizadas se aproveitam.

Para além das questões de mercado, as migrações, de acordo com Sassen 21, são produzidas numa complexa rede de relações não só de cunho econômico, mas também político e cultural. Atualmente tem havido uma feminilização da força de trabalho, visto que a expansão da economia informal cria condições para a mão de obra feminina e estrangeira, não sendo esta economia informal um desvio ou anomalia do sistema, mas fazendo parte das dinâmicas da globalização do desenvolvimento capitalista.

Nos relatos dos representantes institucionais há incertezas quanto às características dessas mulheres traficadas. Eles se baseiam nos poucos casos atendidos ou leituras efetuadas que remetem ao senso comum da mulher pobre que vai "em busca de sonhos" e acaba traficada por promessas ilusórias. Essa percepção é corroborada pelo relatório da Pesquisa sobre Tráfico de Mulheres, Crianças e Adolescentes para Fins de Exploração Sexual Comercial no Brasil 30, que evidenciou um predomínio de mulheres jovens, negras e mestiças, com idade compreendida entre os 15 e os 27 anos. Embora esse relatório tenha contribuído com algum conhecimento sobre essas vítimas de tráfico, ele tem sido alvo de críticas quanto à cientificidade e generalização dos seus dados 31 . Peixoto 32 refere que a emigração brasileira destinada ao negócio do sexo é, sobretudo, de mulheres provenientes dos estratos socioeconômicos baixos que podem não encontrar alternativa de mobilidade ascendente no Brasil.

Alguns entrevistados referiram uma imagem sexualizada da mulher brasileira, pobre e negra, que frequentemente é associada ao mercado do sexo 33,34. Estudos alertam para os cuidados que se deve ter com essa imagem preconceituosa, pois elas podem levar a situações de violação dos direitos humanos das mulheres brasileiras no exterior 22,26,35,36.

Para Blanchette 37 , existe uma representação social em torno da mulher traficada, que o autor denomina de "mito de Maria". São representações que associam, de forma estereotipada, o tráfico de pessoas a características da mulher como: ser mulata ou negra, pobre, do interior ou do Nordeste brasileiro, residente em favela e ingênua.

Com menor frequência, os relatos também mencionaram pessoas de classe média alta como vítimas de exploração sexual na indústria do sexo, o que aponta para a ampliação e complexificação das características deste grupo.

De acordo com Kempadoo 18, apesar de a mídia tentar passar a imagem de que as mulheres foram sequestradas, acorrentadas às camas em 
bordéis e mantidas como escravas sexuais, isto raramente é verificado.

Santos 28 defende que o padrão do tráfico e o perfil das mulheres nele envolvidas não deriva apenas das redes, mas também advém da demanda dos clientes e dos padrões de corpo ideal propagados pela mídia. E essa sua natureza econômica está constituída pelo jogo entre oferta e demanda de serviços sexuais 38 .

Dada a sinergia dos temas tráfico de mulheres para fins de exploração sexual e prostituição, consideramos como uma das limitações do estudo não ter contemplado nenhuma instituição voltada para a defesa dos direitos das profissionais do sexo.

\section{Conclusões}

A definição e as abordagens dos representantes das instituições de referência sobre o tráfico de mulheres para fins de exploração sexual refletem pouco conhecimento teórico conceitual e técnico, e sofrem influências das legislações e das políticas de enfrentamento e acolhimento às vítimas. Essas últimas estão fortemente marcadas pelas diretrizes relacionadas à migração adotada em cada país.

As ambiguidades conceituais e as discrepâncias dos marcos legais (como no caso brasileiro) acabam por influenciar até mesmo a capacida- de discricionária de identificação das vítimas de tráfico.

Como a grande maioria dos casos de tráfico de mulheres para fins de exploração sexual está relacionada à prostituição, é importante considerar que esta é uma atividade nômade que se insere nas dinâmicas da globalização, e isto pode facilitar ou dificultar a travessia de fronteiras segundo a procura e a oferta no mercado do sexo, transformando inclusive o seu perfil. É importante frisar que a construção desse perfil depende das informações que são geradas nas instituições por onde elas passam e, como ficou patente, nem a definição do que é um caso, nem as estatísticas sobre o perfil de mulheres traficadas parecem claras 2,36.

Contudo, a complexidade, os elementos e as dimensões que o tema abrange apontam para a necessidade de aprimoramento tanto no campo teórico como na formação dos profissionais que lidam com esta problemática. Maior precisão conceitual não apenas ajudaria no entendimento do problema, destituindo-o de valores morais, mas nortearia políticas públicas mais adequadas e eficientes, bem como facilitaria a atuação dos técnicos dos vários setores da sociedade que precisam atender, orientar e apoiar as vítimas.

\section{Colaboradores}

J. G. P. E. S. Zúquete redigiu o artigo. E. R. Souza e S. F. Deslandes orientaram a redação e revisaram o artigo.

\section{Agradecimentos}

A todos os representantes institucionais que gentilmente participaram desta pesquisa, mesmo com suas difíceis agendas. À Capes (Bolsa de Doutoramento)/PROAP (passagens e estadia durante a pesquisa no Brasil). 


\section{Referências}

1. Castilho EW. Tráfico de pessoas: da Convenção de Genebra ao Protocolo de Palermo. In: Ministério da Justiça, organizador. Política Nacional de Enfrentamento ao tráfico de pessoas. Brasília: Secretaria Nacional de Justiça, Ministério da Justiça; 2008. p. 10-5.

2. Agustín L. Sex at the margins: migration, labour markets and the rescue industry. London: Zed Books; 2008.

3. Doezema J. Sex slaves and discourse masters: the construction of trafficking. New York: Zed Books; 2010.

4. Jeffreys S. The industrial vagina: the political economy of the global sex trade. New York: Routledge; 2009.

5. InfantaA. Esquema de 'revenda' de vítimas de exploração sexual dribla autoridades na Europa. http:// www.bbc.co.uk/portuguese/noticias/2012/02/ 120130_exploracao_sexual_ai_bg.shtml (acessado em 15/Out/2012).

6. Escritório das Nações Unidas sobre Drogas e Crime; Ministério da Justiça. Relatório nacional sobre o tráfico de pessoas: consolidação dos dados de 2005 a 2011. Brasília: Escritório das Nações Unidas sobre Drogas e Crime/Ministério da Justiça; 2013.

7. Secretaria Nacional de Justiça, Ministério da Justiça. Relatório nacional sobre tráfico de pessoas: dados de 2013. Brasília: Escritório das Nações Unidas sobre Drogas e Crime; 2014.

8. Observatório de Tráfico de Seres Humanos. Relatório anual sobre tráfico de seres humanos 2013. Lisboa: Observatório de Tráfico de Seres Humanos; 2014

9. Minayo MC. O conceito de representações sociais dentro da sociologia clássica. In: Guarechi P, Jovchelovitch S, organizadores. Textos em representações sociais. Petrópolis: Editora Vozes; 1994. p. 89-111.

10. Sampieri R, Collado C, Lucio M. Metedologia de pesquisa. São Paulo: McGraw-Hill; 2006.

11. Minayo MCS. O desafio do conhecimento. São Paulo: Editora Hucitec; 2013.

12. Bardin L. Análise de conteúdo. Lisboa: Edições 70; 2009.

13. Gibbs G. Análise de dados qualitativos. Porto Alegre: Editora Artmed; 2009.

14. Brasil. Lei no 12.015, de 7 de agosto de 2009. Diário Oficial da União 2009; 10 ago.

15. Faria TD. Mulheres no tráfico de pessoas: vítimas e agressoras. Cadernos Pagu 2008; (31):151-72.

16. Teresi VM. La lucha contra la trata de personas en la cooperación hispano-brasileña. Revista Española de Desarrollo y Cooperación 2008; 22:183-94.

17. Goldman E. Anarchism and other essays. New York: Dead Dodo Vintage; 2013. Kindle edition.

18. Kempadoo K. Mudando o debate sobre o tráfico de mulheres. Cadernos Pagu 2005; (25):55-78.

19. Oliveira MPP. Sobre armadilhas e cascas de banana: uma análise crítica da administração de Justiça em temas associados aos Direitos Humanos. Cadernos Pagu 2008; (31):125-49.
20. Piscitelli A. Entre a Praia de Iracema e a União Européia: turismo sexual internacional e migração feminina. In: Piscitelli A, Gregori MF, Carrara S, organizadores. Sexualidades e saberes, convenções e fronteiras. Rio de Janeiro: Garamond; 2004, p. 250-70.

21. Sassen S. Contrageografías de la globalización. Géneros y ciudadanía en los circuitos transfronteirizos. Madrid: Traficantes de Suenõs; 2003.

22. ASBRAD. Direitos Humanos e gênero no cenário da migração e do tráfico internacional de pessoas. Cadernos Pagu 2008; (31):251-73.

23. Piscitelli A. Entre as "máfias" e a "ajuda": a construção de conhecimento sobre tráfico de pessoas. Cadernos Pagu 2008; (31):29-63.

24. Grupo Davida. Prostitutas, "traficadas" e pânicos morais: uma análise da produção de fatos em pesquisas sobre o "tráfico de seres humanos". Cadernos Pagu 2005; (25):153-84.

25. Sabino C, Murteira S. O tráfico de migrantes em Portugal: perspectivas sociológicas, jurídicas e políticas. Lisboa: Acime; 2005.

26. Filho W. Os dois lados - macro-narrativas possíveis do tráfico de brasileiras para a prostituição em Portugal e a sua representação na mídia tabloidizante. http://www.bocc.ubi.pt (acessado em 12/ Abr/2012).

27. Santos B. Tráfico de mulheres para fins de exploração sexual em Portugal: um retrato empírico. In: Observatório de Tráfico de Seres Humanos, organizador. Tráfico desumano. Lisboa: Observatório de Tráfico de Seres Humanos; 2010. p. 89-114. (Coleção de Direitos Humanos e Cidadania).

28. Santos B. Tráfico de mulheres em Portugal para fins de exploração sexual. Lisboa: Comissão de Igualdade de Gênero; 2008. (Coleção Estudos de Gênero).

29. Malarek V. The Natashas: inside the new global sex trade. New York: Arcade Publishing; 2004.

30. Leal ML, Leal MF, organizadores. Pesquisa sobre Tráfico de Mulheres, Crianças e Adolescentes para fins de Exploração Sexual Comercial - PESTRAF. Relatório final. Brasília: Centro de Referência, Estudos e Ações sobre Crianças e Adolescentes; 2002.

31. Blanchette T, Silva AP. As rotas da PESTRAF: empreendedorismo moral e a invenção do tráfico de pessoas no Brasil. Revista Ártemis 2014; XVIII:12-27.

32. Peixoto J. Tráfico, contrabando e imigração irregular. Os novos contornos da imigração brasileira em Portugal. Sociologia, Problemas e Práticas 2007; (53):71-90.

33. Piscitelli A. Actuar la brasileñidad? Tránsitos a partir del mercado del sexo. Etnográfica 2011; 15:5-29.

34. Pontes L. Mulheres brasileiras na mídia portuguesa. Cadernos Pagu 2004; (23):229-56. 
35. Alvim F, Togni P. Sob o véu dos direitos humanos: tráfegos, tráficos e políticas públicas para a imigração. Um estudo de caso sobre as mulheres brasileiras em Portugal. In: Anais Fazendo Gênero 9: Diásporas, Diversidades, Deslocamentos http:/ / www.fazendogenero.ufsc.br/9/resources / anais/1277741002_ARQUIVO_Comunicacao CompletaFG9_SoboveudosDireitosHumanos.pdf (acessado em 12/Abr/2013).

36. Santos B, Gomes C. Duarte M. Tráfico sexual de mulheres: representações sobre ilegalidade e vitimação. Revista Crítica de Ciências Sociais 2009; (87):69-94.
37. Blanchette T, Silva AP. O mito da Maria, uma traficada exemplar. Revista Interdisciplinar da Mobilidade Humana 2011; XIX:79-106.

38. Piscitelli A. Corporalidade em confronto: brasileiras na indústria do sexo na Espanha. Rev Bras Ciênc Soc 2007; 22:17-32.

\begin{abstract}
This study focuses on concepts involved in women trafficking for sexual exploitation according to representatives of government and nongovernmental institutions working with policies to confront and prevent trafficking and assist victims in Brazil and Portugal. An exploratory qualitative study was performed to identify the institutional discourses on women trafficking using thematic analysis. Interviewees displayed conceptual imprecision concerning women trafficking, sometimes ignoring the rights of sex workers to migrate and work in other countries. There is no consensus among the institutions on the profile of trafficking victims, marked by stereotypes, and the definition is influenced by legislation and border controls. Greater conceptual precision would minimize the role of moral values, orient more adequate and efficient public policies, and facilitate staff action in assisting victims.
\end{abstract}

Human Trafficking; Sexual Violence; Crime Victims; Women

\section{Resumen}

Este artículo investiga las concepciones sobre el tráfico de mujeres para fines de explotación sexual, desde la óptica de representantes de instituciones gubernamentales y no gubernamentales, que actúan en la construcción de políticas de lucha, en la prevención y en la acogida de las víctimas, en Brasil y en Portugal. Se efectuó un estudio exploratorio de naturaleza cualitativa, con el objetivo de identificar los discursos institucionales referentes a las concepciones sobre el tráfico de mujeres para fines de explotación sexual, a través de un análisis temático. Se observó imprecisión conceptual en las concepciones de los entrevistados sobre tráfico de mujeres para fines de explotación sexual, ignorando a veces los derechos de las trabajadoras sexuales en emigrar para trabajar en otros países. No existe consenso entre las instituciones sobre el perfil de víctima de tráfico, marcado por estereotipos, su delimitación es influenciada por la legislación y por el control de fronteras. Una mayor precisión conceptual minimizaría el papel de valores morales, dirigiría políticas públicas más adecuadas y eficientes, así como facilitaría la actuación de los técnicos en la atención a las víctimas.

Trata de Personas; Violencia Sexual; Víctimas de Crimen; Mujeres
Recebido em 12/Mai/2015

Versão final reapresentada em 22/Fev/2016

Aprovado em 22/Mar/2016 